\section{Rescuing Fundamental Science in the CIS}

Initiatives to help preserve fundamental dent States (CIS) include the World Lab programme (which held a Projects Convention last month in Erice, Italy, chaired by $\mathrm{A}$. Zichichi, the World Lab's President, to discuss new actions) and efforts to launch an international foundation for Russia [EN 22 (1991) 166].

With regard to the foundation, leading scientists have approached governments in the west to raise support for the foundation. For instance, C. Rubbia, CERN's Director-General, has written to François Mitterrand, the French President, who indicated that his government agreed in principle to contribute 10 M\$US to a foundation, and that it would put the item before the European Community. L. Okun, a high-energy physicist at ITEP in Moscow and a leading promoter of the foundation, reports that the Finnish government had also shown considerable interest during a recent visit he made to Helsinki.

Professor A.F. Andreev, Vice-President of the Russian Academy of Sciences and a member of the EPS Executive Committee, speaking in Lieden while on a sabbatical leave stated in no uncertain terms that the foundation meets with the full approval of the Russian Prime Minister, Foreign Minister and Academy of Sciences. He too has also discussed details with western agencies, in this case with the Dutch Academy of Sciences which said it would try to enlarge support for the proposal.

\section{First Steps}

A list of names of experts from Russia and the west has been drawn up as the basis for nominating some 30 committees. The proposal is to make these committees responsible for distributing the foundation's funds in a bottom-up fashion. Operating out of western laboratories and centres, they would be fully independent of "bureaucratic black holes". Some 100 M\$US is thought necessary for the first year. Requirements include a commitment from the Russian government that existing internal funding of science would not be reduced if external support was forthcoming, and that arbitrary taxes are not imposed (the present legal framework being very patchy).

With help on this scale, Professor Okun thinks it should be possible to keep 5000 Russian research workers active (and not simply in "a survival mode") in collaborative arrangements with western groups. $\mathrm{He}$ also envisages other forms of activities supported financially from abroad, such as the creation of international centres and schools, and help in supplying equipscience in the Commonwealth of Indepen- ment as participation in large projects for science.

With all this activity, why the Aosta Appeal (see below)? Professor Okun says the German-US Genscher/Baker initiative to support strategic sciences, such as nuclear physics, has become confused with the foundation for basic science which has very different objectives. It had become necessary to "discriminate" between proposals for "the military and for fundamental science".

\section{Short-Term Measures Essential} port schemes, Professor Andreev felt it is important that western agencies retain as much control as possible to avoid misspending. Second, he argued that the Genscher/Baker scheme, and maybe the foundation, will take some time to set up as financial and legal implications need to be settled at the government level. So
Commenting on the relatively large sup- short-term measures are required in the face of a potentially disastrous situation.

Professor Andreev stressed that some of the problems facing scientists in the $\mathrm{CIS}$ can be tackled effectively by having a third (western) partner involved. He cited the case of astronomers: while mainly based in Russia (notably in Moscow and St. Petersburg), their observatories and telescopes are located in the Republics. A "treaty is clearly necessary" to resolve the issue. But while the problem is serious it is not the most pressing.

Another way to provide immediate help is to employ research staff from the CIS for short periods on collaborative projects in the west. Surplus income can at present be transferred to the CIS without tax liabilities and used to supplement meager wages (\$US 20 for a professor) and to purchase equipment. However, as with thirdworld aid programmes, it is important that a scientist has something solid to return to: hence the importance of a longer term collaboration at the group level.

$\mathrm{He}$ argued that the best way forward is to extend the many collaborative arrangements already in place, and cited some

\section{Aosta Appeal}

The following is a text of an appeal formulated during a round-table discussion at this year's Rencontres de Physique de la Vallée d'Aoste held at La Thuile on 8-14 March. Participants included V. Soegel, R. Schwitters, B. Pontecorvo, S. Belyaev, A. Skrinski, L. Okun, and R. Klapisch.

We, a group of physicists from many countries all over the world, gathered at La Thuile, in the Aosta Valley, on the occasion of the 6th Rencontres de Physique de la Vallée d'Aoste, express our extreme concern and call for urgent steps on all possible levels to rescue fundamental science in Russia.

We call on the Russian Government to undertake all possible measures in order to save Russian fundamental science, a precious and unique part of world science and culture.

We call on Governments of all industrial countries (especially in Europe) to create an International Foundation for the support of fundamental science, both theoretical and experimental, in Russia. With a ruined scientific community, Russia would have no future, and could not be integrated with the world democracies. The existing Russian scientific community can play an important rôle in this integration. The close ties between scientists of Republics of the former Soviet Union could be an important factor preventing its further fractalization.

We call on all National Academies and Scientific Societies to take an active rôle in their interaction with their governments and their Russian counterparts in order to expand bilateral and multilateral scientific projects and exchanges.

We call on funding agencies, universities, and national laboratories in the West to promote and organize exchanges, workshops and collaborations with their Russian colleagues. This would help to use not only Russian scientific potential, but also to steer the potential of Russian high-tech industry and help to reorient it from mostly military to civilian applications.

We call on individual scientists to assume their responsibility and to suggest new forms, new projects, however modest they may be, of collaboration with their Russian colleagues, in their attempts to prevent disaster. The lack of funds for obtaining such equipment as computers, computer links and experimental tools in general, and the lack of foreign journals and books, are having a paralyzing effect on Russian scientists and must be remedied.

A massive exodus of the best Russian scientists would lead to rapid destruction of the scientific centres and unique scientific schools in Russia, and would have a catastrophic effect on education in universities, colleges and high schools.

The "brain drain" from Russia will give only a transitional "brain gain" in the West. To use Russian science as a disposable product would be a great and tragic mistake. 


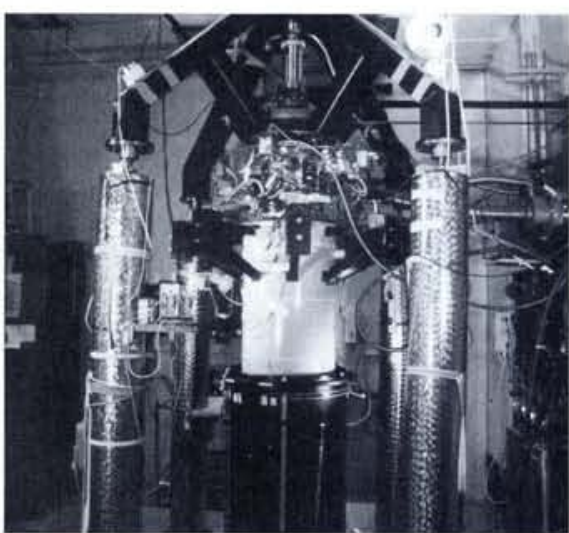

The ROTA 2 rotating liquid helium cryostat at the Helsinki University of Technology.

examples in his own field of low-temperature physics (noting that its situation is perhaps exceptional). A formal collaboration exists between the I.V. Kurchatov Institute for Atomic Energy which has large departments for low-temperature physics and technology (with 3000 staff members it is the world's largest institute in the field), the Physics Institute in Tbilissi, Georgia, his own P.L. Kapitza Institute for Physical Problems in Moscow, and the Helsinki University of Technology. The collaboration was set up to build and operate the ROTA 2 rotating liquid helium cryostat [EN 22 (1991) 3]. An agreement required the former Soviet Union to supply liquid helium but this has now become extremely difficult to obtain in the CIS. Working conditions in Tbilissi have also "become impossible". Nevertheless, the collaboration continues, and like other existing collaborations, can be expanded within the short term "without complication".

\section{East-West Coordination Committee}

The East-West Coordination Committee (EWCC) of EPS, formerly the EPS East-West Task Force, comprises:

Chairman:

A. Landesman

Les Editions de Physique

Ave. du Hoggar

Z.I. de Courtabœuf, BP 112

F-91944 Les Ullis Cédex A

Tel./Fax: + 33 (1) 69073688 / 69288491

Secretary:

E.W.A. Lingeman

NIKHEF

Postbus 4395

NL-1009 AJ Amsterdam

Tel./Fax: + 31 (20) $5922117 / 5922165$

ed@nikhefk.nikhef.nl

Members: I. Abonyi, Budapest

M. Mateev, Sofia

J. Nadrchal, Prague

O. Gherman, Craiova

J. Spalec, Warsaw

I. Slaus, Zagreb

W. Lock, CERN

Observers: G. Ripka, Saclay

J. Ziman, London

\section{Unique Russian Training Scheme at Risk}

\begin{abstract}
"Naive privatisation" in Russia is putting at risk a cornerstone of the country's higher education in physics. How is this? The problem concerns an unique training scheme which is relatively unknown abroad. It was set up in 1946 by P.L. Kapitza and L. Landau. Under the scheme, many Russian physics and engineering students (some 6000) aiming for research and postgraduate training are enrolled and housed at the Moscow Physical-Technical Institute (MPTI) at Dolgo Pradnaya just outside the city after a competitive entrance exam (Siberia has an equivalent institute on a large campus at Novosibirsk). The students attend basic courses given by MPTI staff during the first year. In the second year, they start spending a day a week in one of the region's 50 or so research institutes, which may belong to either a ministry or to the Russian Academy of Sciences.
\end{abstract}

Each institute has "chairs" made up of the staff members who teach students. Each chair has a chairman, and a full hierarchy of positions (head, full professor, etc.) and its members, typically 10 in number, are appointed jointly by the institute and the Council of the MPTI; some chair members also teach at the MPTI. Members are usually recommended for appointment by the MPTI based on teaching skills or by virtue of being a leader of a research group. Students apply to individual institutes which make their own selection to fill preset quota.

The time spent at the institute rises to five days each week by the fifth and sixth years when a diploma thesis is written and defended in the institute. L. Okun, a particle physicist who heads a chair in ITEP, the Institute for Theoretical and Experimental Physics, notes that some students are actively engaged in research projects by the fourth year, and that a Ph.D. can in principle be awarded only one year after the diploma (3-4 years is more normal for a theoretical thesis, and 7-8 for an experimental one).

So the system can be highly motivating, as witnessed by the many eminent Russian physicists who received their training this way. They include the present Russian Minister of Science, L.P. Gorkov (solidstate theory); M. Boloschin, A. Migdal, A. Polyakov, M. Shifman (particle physics); A. Doglov, R. Sunyaev (space, astrophysics). Well-known heads of chairs include Yu.A. Ossipyan, L.P. Gorkov, S. Belyaev, and Academician Abricosov.

The Kapitza-Landau system undoubtedly offers many advantages: young people stay close to research and grow into the research system; undergraduates have experts as teachers, enter the spirit and life of the institute, and are often selected for staff positions during their training.

But is the model viable for future? At present, the system is fairly stable, chairs included, although the number of students ap-

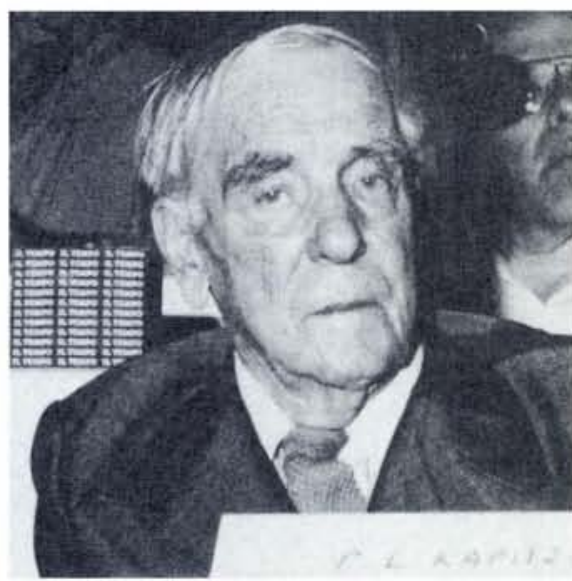

P.L. Kapitza

plying to MPTI is decreasing. More disturbing is the "privatisation" where the research institutes are increasingly expected to pay the universities and institutes other than the MPTI for the students they are sent (the MPTI remains by far the predominant partner as the universities and other institutes are only responsible for about $20 \%$ of the scheme's students). Having a large central organisation charged with teaching and no research has drawbacks, and contrasts with the large, conventional universities that have research integrated into the academic structure. These include Moscow State and St. Petersburg - each with some 20000 students spread over all facilities, not just science and engineering. The Kapitza-Landau system of research training may also seem to be elitist and focussed on a limited view of research training. But by its very success, it does at least shatter the stereotype that the only correct place to do fundamental research is in the universities.

\section{Science Policy and Management}

\section{PROCEEDINGS AVAILABLE}

The proceedings, edited by E.W.A. Lingeman, of the Europhysics Study Conference "Science Policy and Management" held at Schloss Dagstuhl, Germany, on 18-21 August 1991 can be ordered from the EPS Geneva Secretariat. The price is SFR 50. - plus postage (participants will each receive a free copy).

The proceedings represent a goldmine of information. They include invaluable and detailed presentations by representatves of nine major European research funding organisations together with analyses of general issues. 